\title{
Mechanical characteristics of plastic base Ports and impact on flushing efficacy
}

\author{
Gérard Guiffant' \\ Patrice Flaud' \\ Laurent Royon' \\ Espérie Burnet ${ }^{2}$ \\ Jacques Merckx ${ }^{1-3}$ \\ 'University Paris Diderot, Biofluidic \\ Group, UMR CNRS, ${ }^{2}$ Pulmonary \\ Department and Adult Cystic Fibrosis \\ Centre, Cochin Hospital, ${ }^{3}$ University \\ Teaching Hospital, Necker-Enfants \\ Malades, Paris, France
}

This article was published in the following Dove Press journal:

Medical Devices: Evidence and Research

17 January 2017

Number of times this article has been viewed

Background: Three types of totally implantable venous access devices, Ports, are currently in use: titanium, plastic (polyoxymethylene, POM), and mixed (titanium base with a POM shell). Physics theory suggests that the interaction between a non-coring needle (NCN, made of stainless steel) and a plastic base would lead to the stronger material (steel) altering the more malleable material (plastic).

Objectives: To investigate whether needle impacts can alter a plastic base's surface, thus potentially reducing flushing efficacy.

Study design and methods: A Port made of POM was punctured 200 times with a 19-gauge NCN. Following the existing guidelines, the needle tip pricked the base with each puncture. The Port's base was then examined using a two-dimensional optical instrument, and a bi-dimensional numerical simulation using $\mathrm{COMSOL}^{\circledR}$ was performed to investigate potential surface irregularities and their impact on fluid flow.

Results: Each needle impact created a hole (mean depth, $0.12 \mathrm{~mm}$ ) with a small bump beside it (mean height, $0.02 \mathrm{~mm}$ ) the Reynolds number $\mathrm{Re}_{\mathrm{k}} \approx 10$. A numerical simulation of the one hole/bump set showed that the flushing efficacy was $60 \%$ that of flushing along a flat surface.

Discussion: In clinical practice, the number of times a Port is punctured depends on patient and treatment characteristics, but each needle impact on the plastic base may increase the risk of decreased flushing effectiveness. Therefore, the more a plastic Port is accessed, the greater the risk of microorganisms, blood products, and medication accumulation.

Conclusions: Multiple needle impacts created an irregular surface on the Port's base, which decreased flushing efficacy. Clinical investigation is needed to determine whether plastic base Ports are associated with an increased risk of Port infection and occlusion compared to titanium base Ports.

Keywords: TIVAD, plastic Port, polyoxymethylene, flushing, infection, occlusion

\section{Introduction}

Totally implantable venous access devices (TIVADs) have been in use for more than three decades. They have proven to be safe and effective. Their indications, complications, and maintenance guidelines are well described and widely accessible ${ }^{1-11}$ There are currently three types of TIVADs (further referred to as Ports) available: metal (titanium), plastic (polyoxymethylene [POM]), and mixed (titanium base with a POM shell). Physics theory suggests that, when accessing a plastic base Port, the interaction between the metal non-coring needle ( $\mathrm{NCN}$, made of stainless steel) and the plastic base, the stronger material (steel) would alter the more malleable material (plastic). Given that Port access guidelines clearly state that when inserting an NCN, the Port's

Correspondence: Gérard Guiffant University Paris Diderot, MSC, UMR CNRS 7057, 10 rue Alice, Domon et Léonie Duquet, Cedex 13, 75205 Paris, France

Fax +33 I 5727621 I

Email gerard.guiffant@univ-paris-diderot.fr 
base must be felt ${ }^{12,13}$ and repeated punctures could alter the integrity of a plastic base's surface.

The aim of this study is to investigate whether stainless steel needle impacts on a plastic (POM) base can lead to the alteration of the base's surface and therefore to local modifications in fluid flow within the Port.

\section{Materials and methods}

A Port, made of POM, was punctured 200 times with a 19-gauge NCN by the same participant. ${ }^{14}$ As recommended in the existing guidelines, the needle's beveled tip pricked the base with each puncture. The Port was then taken apart and its base was examined using a two-dimensional optical instrument with magnification powers of 21 and 147. A bi-dimensional numerical simulation using $\mathrm{COMSOL}^{\circledR}$ was performed to investigate the potential impact of surface irregularities on flow characteristics along the Port's base. The dimensions of the surface irregularities (holes and bumps) were obtained using image analysis (ImageJ). The mean depth of the holes and mean height of the bumps were calculated. The retained parameters for fluid flow were $U \approx 0.5 \mathrm{~m} / \mathrm{s}$ for the mean input velocity in the Port and $v \approx 10^{-6} \mathrm{~m}^{2} / \mathrm{s}$ for the viscosity of the flushing fluid.

\section{Results}

Figure $1 \mathrm{~A}$ and $\mathrm{B}$ shows a magnified view $(\times 21)$ of the plastic Port's base, which has a bumpy and rugged aspect, confirmed with a greater magnification $(\times 147)$. In the absence of any other intervention, the bumps and holes are clearly the result of the needle tip impacts. The mean depth of the holes was $0.12 \mathrm{~mm}$ and the bumps had a mean height of $0.02 \mathrm{~mm}$. These values yield a Reynolds number, associated with the flow along a rough surface, of $\operatorname{Re}_{\mathrm{k}}=\frac{\mathrm{k}_{\mathrm{s}} \mathrm{U}}{\mathrm{v}}$, where $\mathrm{k}_{\mathrm{s}}$ is the dimension of the bump $\left(\mathrm{k}_{\mathrm{s}}=2 \times 10^{-5} \mathrm{~m}\right), \mathrm{v} \approx 10^{-6} \mathrm{~m}^{2} / \mathrm{s}$

A

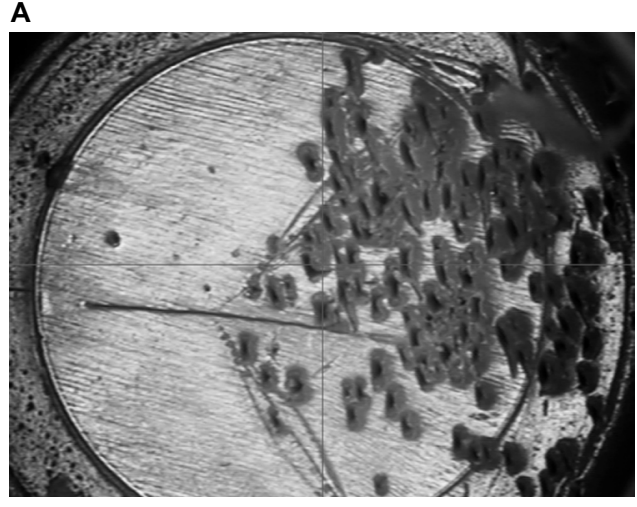

is the viscosity of the flushing fluid (normal saline), and $\mathrm{U} \approx 0.5 \mathrm{~m} / \mathrm{s}$ is the velocity in the vicinity of the Port's base. In clinical situations, this velocity is associated with mean input flows ranging from 0.2 to $1 \mathrm{~mL} / \mathrm{s} .{ }^{15}$ The retained parameters lead to $\mathrm{Re}_{\mathrm{k}} \approx 10$. This value lies in the transition interval of $5<\operatorname{Re}_{\mathrm{k}}<70$, indicating that roughness may be associated with altered flow patterns and, in fine, with decreased flushing efficacy.

A rough estimate of the shear rate in the immediate vicinity of the needle tip was obtained and used as an input parameter in the numerical simulation. If the aperture of the needle has an elliptical shape (Figure 2) with a semi-major axis of $a=1.97 \mathrm{~mm}$ for a 19-gauge needle (and $b=0.35 \mathrm{~mm}$, semi-minor axis), then the shear rate on the Port's base at the outlet of the needle tip can be calculated as $\dot{\gamma}_{\mathrm{i}} \approx \mathrm{U} / \mathrm{a} \approx 250 \mathrm{~s}^{-1}$. Figure 3 shows the geometry used for the simulation. The surface irregularities of the Port's base consist of a succession of holes and bumps with the previously defined dimensions. The simulation was conducted for stationary solutions by applying a linear velocity profile with a shear rate $\dot{\gamma}_{i}$ as a boundary condition at the entry of the flow.

Figure 3 shows the flow lines obtained from the numerical simulation. The direction of the flow was chosen arbitrarily (from right to left). The observed flow line constriction above the bump, associated with an enlargement just before and after, is a common situation encountered when studying streamlines around obstacles. ${ }^{16}$

More importantly, and of great clinical relevance for flushing effectiveness in clinical settings, the flow lines did not enter the hole, leading to a recirculating flow in the cavity. In other words, closed streamlines appeared in the hole as rotating cells of fluid (driven cavity flows) and had a marked effect on mass transport between the main flow and the cavity. ${ }^{17}$ The result was decreased flushing effectiveness.

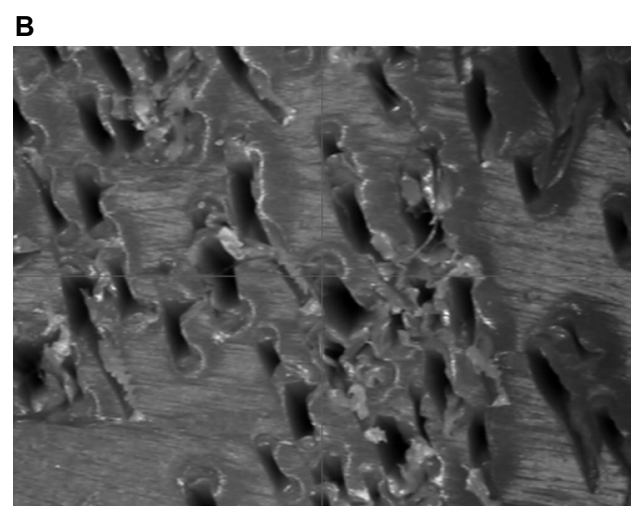

Figure I Magnified view of the plastic Port base; $(\mathbf{A} ; \times 2 \mathrm{I})$ and $(\mathbf{B} ; \times \mid 47)$. Note: Source: Perouse Medical $\subset$. 


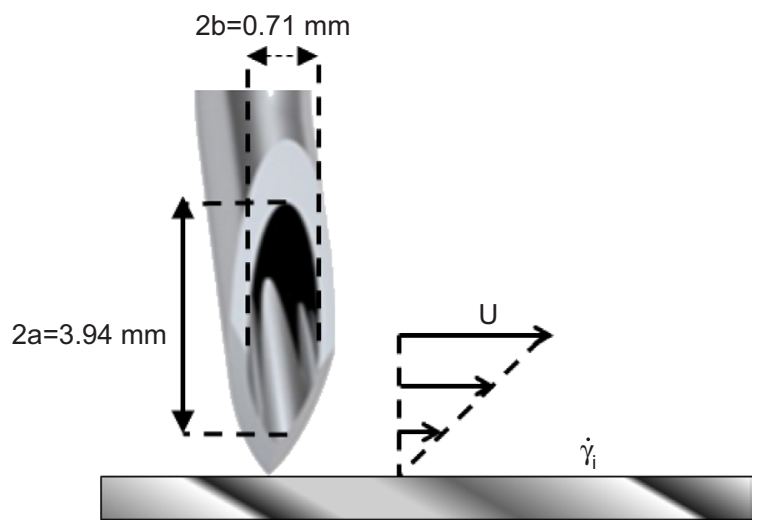

Figure 2 View of the elliptical aperture of the needle with a representation of the velocity profile in the immediate vicinity of the Port base.

Notes: $\mathrm{a}$ and $\mathrm{b}=$ semi major and minor axis; $\mathrm{U}=$ mean input velocity; $\dot{\gamma}_{\mathrm{i}}=$ shear rate.

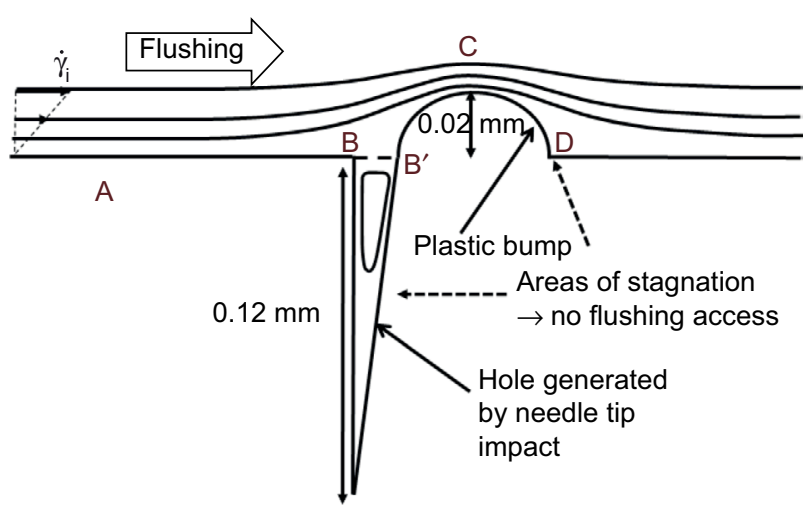

Figure 3 Geometry used for the numerical simulation and representation of the flow lines around and in the vicinity of the succession of a hole and a bump. Notes: $\dot{\gamma}_{i}=$ shear rate; $A, B, B^{\prime}, C, D=$ position along the limit.

Figure 4 shows the distribution of the wall shear rate along the base in the vicinity of the irregularities. Points A, $\mathrm{B}, \mathrm{B}^{\prime}, \mathrm{C}$, and $\mathrm{D}$ represent positions along the limit and are also shown in Figure 3. The interval $\mathrm{BB}^{\prime}$ corresponds to the hole's aperture. The wall shear rate increases significantly above the bump (position $\mathrm{C}$, constriction of the streamlines). Positions B, B', and D are associated with very low wall shear rate values (widening of the stream lines). This distribution of wall shear rates would occur around obstacles, such as drug deposits, blood products, and contrast media. ${ }^{16}$

Furthermore, the wall shear rate is closely related to the velocity distribution near the base. A numerical simulation can follow the variation of the velocity profile, perpendicularly to the wall, along the distribution of the surface irregularities. Results are shown in Figure 5, where $\mathrm{z}$ denotes a coordinate perpendicular to the wall. The most striking result is the transition of the velocity profile from a linear profile $(\mathrm{U} \approx \mathrm{z})$ above the flat part of the wall to a logarithmic velocity profile $\left(\mathrm{U} \approx \operatorname{Ln}\left(\mathrm{z} / \mathrm{k}_{\mathrm{s}}\right)\right.$ ) above the irregularities. This

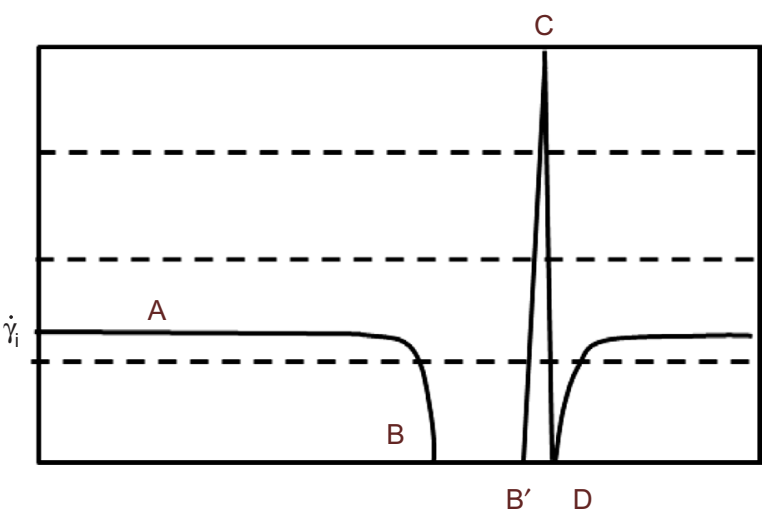

Figure 4 Distribution of the wall shear rate along the base in the vicinity of the irregularities.

Notes: $\dot{\gamma}_{i}=$ shear rate; A, B, B', C, D = position along the limit.
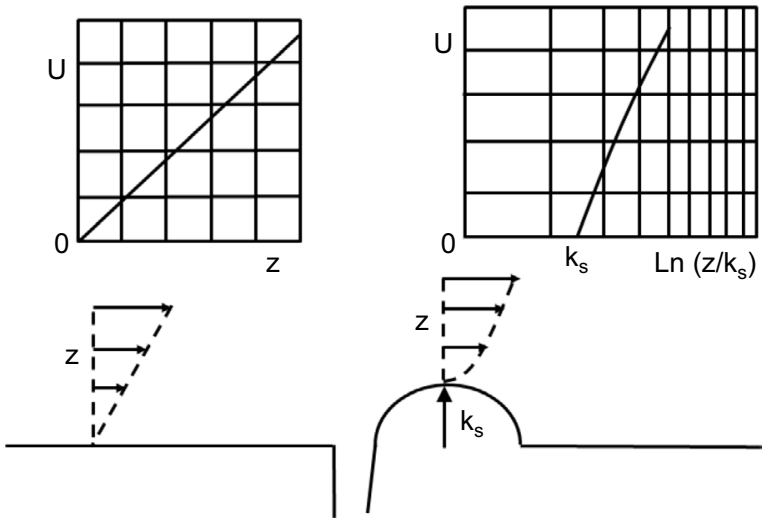

Figure 5 Modification of the velocity profile above the bump.

Notes: $U$ =mean input velocity; $z=$ vertical coordinate; $k_{s}=$ dimension of the bump. Abbreviation: Ln, logarithm.

last point is essential as it is a hydrodynamic signature of the impact of the needle tip on a plastic base. As seen in the simulation (Figure 3), the streamlines never penetrate the hole and the positions just before and just after the bump (positions $\mathrm{B}^{\prime}$ and $\mathrm{D}$ in Figure 3 ) are also inaccessible to flushing (Figure 4).

A phenomenological examination of wall shear rate modifications along a rough surface provides an indication of flushing efficacy and a logarithmic velocity profile can be obtained, satisfying the boundary conditions against the wall $\mathrm{v}=\mathrm{U} \frac{\mathrm{Ln}\left(\mathrm{z} / \mathrm{k}_{\mathrm{s}}\right)}{\operatorname{Ln}\left(\mathrm{a} / \mathrm{k}_{\mathrm{s}}\right)}$. We can then calculate the ratio $\mathrm{G}$ of the mean wall shear rate over the wall in the conditions of flow at the outlet of the NCN with respect to the main wall shear rate $\mathrm{G}=\operatorname{Ln}\left(\mathrm{a} / \mathrm{k}_{\mathrm{s}}\right) \frac{(\mathrm{a} / \mathrm{h})}{\left(\mathrm{aLn}\left(\mathrm{a} / \mathrm{k}_{\mathrm{s}}\right)-\mathrm{a}+\mathrm{k}_{\mathrm{s}}\right)}$. Taking the numerical values previously used, this results in $\mathrm{G} \approx 0.6$. In other words, in the vicinity of bumps and holes, flushing efficacy is $60 \%$ that of flushing along a flat surface. 
These results show that multiple needle impacts on the base of plastic Ports can potentially significantly hinder flushing effectiveness, which is associated with increased risks of occlusion and infection.

\section{Discussion}

For practical purposes, the flow analysis conducted in this study focused on one hole and bump set, resulting from one needle puncture. With each additional puncture, the affected surface area of the Port base will increase, thus leading to a progressive decrease in flushing effectiveness and to an increased risk of microorganisms, blood products, and medication getting trapped either in the hole or in the bump's vicinity. In practice, the number of times a Port is accessed depends on the treatment it is used for. For patients receiving frequent or prolonged intravenous therapy, the number of punctures may be as high as 50 or 100 per year. Indeed, according to international guidelines, the NCN must be changed every 7 days when the Port is used on a continuous basis. For intermittent treatments, a new needle may be used (and removed) twice a week or more. Thus, for patients requiring a heavy treatment regimen, the number of punctures can be quite high. In these patients, the use of a plastic base Port could significantly increase the risk of colonization and occlusion. It is worth noting that the in vitro design of this study cannot account for other factors related to the patient, illness, treatment, or caregiver, all of which play an important role in needle change frequency and on flushing effectiveness. Nonetheless, the analysis of material interaction and fluid flow from a physics perspective remains clinically relevant and warrants further exploration in a clinical setting.

In addition, two studies have reported POM perforation from repeated needle punctures. ${ }^{12,13}$ Although quite rare, and not observed in our study, such events support our results and confirm material displacement with each needle impact. A systematic examination of POM Port base surfaces after their removal is clearly indicated, as is the use of titanium base Ports for patients who are likely to receive prolonged treatment.

Furthermore, because Port access guidelines clearly state that the Port's base must be felt when inserting the needle, preventing or minimizing the risk of altering the plastic Port's base by not pricking it with the needle tip cannot be recommended. Indeed, this would increase the risk of extravasation, a far more severe complication. Ensuring that flushing is effective by increasing the volume used in plastic base Ports may be indicated, although further research should be undertaken to determine whether increasing the flushing volume is sufficient to prevent complications.

\section{Conclusion}

The in vitro evaluation of surface conditions in plastic base Ports shows that each puncture by a metal needle creates a hole and bump set, which decreases flushing efficacy, potentially leading to an increased risk of Port occlusion and infection. ${ }^{18}$ Indeed, the observed holes and bumps were of sufficient size to alter fluid flow along the base's surface. Over time, and with frequent use of the Port, the cumulative effect of the needle tip impacts could lead to the creation of a matrix, subsequent accumulation of microorganisms, proteins and molecules, and concurrently decreased flushing effectiveness. Further exploration is necessary to determine whether this could result in clinical complications. To reduce the risk of altering the base's surface, needle insertion in plastic base Ports should be performed with care, although this may be difficult to implement in clinical practice. In any case, plastic base Ports should be indicated for short-term treatment only.

\section{Disclosure}

The authors report no conflicts of interest in this work.

\section{References}

1. Adler A, Yaniv I, Steinberg R, et al. Infectious complications of implantable ports and Hickman catheters in paediatric haematology-oncology patients. J Hosp Infect. 2006;62(3):358-365.

2. Ahmadi J, Izadyar M, Ashjaei B, et al. Study of advantages and disadvantages of totally implantable venous access device. Acta Medica Iranica. 2006;44(3):199-202.

3. Hall P, Cedermark B, Swedenborg J. Implantable catheter system for long-term intravenous chemotherapy. J Surg Oncol. 1989;41(1):39-41.

4. Herrmann KA, Waggershauser T, Sittek H, Reiser MF. Liver intraarterial chemotherapy: use of the femoral artery for percutaneous implantation of catheter-port systems. Radiology. 2000;215(1):294-299.

5. Hirota T, Yamagami T, Tanaka O, et al. Brain infarction after percutaneous implantation of port-catheter system via the left subclavian artery. Br J Radiol. 2002;75(898):799-804.

6. Yamagami T, Kato T, Iida S, Hirota T, Nishimura T. Management of end hole in placement of port-catheter system for continuous hepatic arterial infusion chemotherapy using the fixed catheter tip method. AJR Am J Roentgenol. 2005;184(4):1332-1339.

7. Yamagami T, Terayama K, Yoshimatsu R, Matsumoto T, Miura H, Nishimura T. Use of N-butyl cyanoacrylate in implantation of a portcatheter system for hepatic arterial infusion chemotherapy with the fixed-catheter-tip method: is it necessary? AJR Am J Roentgenol. 2008; 191(5):1523-1529.

8. Matillon Y. [Quality assessment of the use and monitoring of implantable ports]. ANAES. 2001:1-57. French.

9. Baskin JL, Pui CH, Reiss U, et al. Management of occlusion and thrombosis associated with long-term indwelling central venous catheters. Lancet. 2009;374(9684):159-169.

10. Pittiruti M, Hamilton H, Biffi R, MacFie J, Pertkiewicz M; ESPEN. ESPEN guidelines on parenteral nutrition: central venous catheters (access, care, diagnosis and therapy of complications). Clin Nutr. 2009; 28(4):365-377.

11. Ragni MV, Journeycake JM, Brambilla DJ. Tissue plasminogen activator to prevent central venous access device infections: a systematic review of central venous access catheter thrombosis, infection, and thromboprophylaxis. Haemophilia. 2008;14(1):30-38. 
12. Dillon PA, Foglia RP. Complications associated with an implantable vascular access device. J Pediatr Surg. 2006;41(9);1582-1587.

13. Sharp NE, Knot EM, Thomas P, Rivard DC, Peter SD. Burden of complications from needle penetration of plastic ports in children.J Pediatr Surg. 2014;49(5);763-765.

14. Jullien A. Impact des ponctions répétées en matière de contamination particulaires entre chambre implantable plastique ou titane [Impact of repeated punctures on particulate contamination for plastic or titanium implantable ports] [Hydrodynamics and distal pollution of vascular accesses]. Euro-Pharmat. 2015. French.
15. Guiffant G, Dupont C, Merckx J. Impact of the shape of the needle tip on the efficacy of flushing implantable port chambers. $J$ Vasc Access. 2016;17(6):521-526.

16. Guiffant G, Flaud P, Merckx J. Hydrodynamique et pollution distale des accès vasculaires. Sang Thrombose Vaisseaux. 2012;24;1;19-22. French.

17. Guiffant G. Rôle des écoulements de recirculation sur les processus de transfert [Thèse de Doctorat] [Role of recirculation flows on transfer processes, PhD Thesis]. Paris, France: Université Paris VII; 1982. French.

18. Goossens GA. Flushing and locking of venous catheters: available evidence and evidence deficit. Nurs Res Pract. 2015;2015:985686.
Medical Devices: Evidence and Research

\section{Publish your work in this journal}

Medical Devices: Evidence and Research is an international, peerreviewed, open access journal that focuses on the evidence, technology, research, and expert opinion supporting the use and application of medical devices in the diagnosis, monitoring, treatment and management of clinical conditions and physiological processes. The identification of novel

\section{Dovepress}

devices and optimal use of existing devices which will lead to improved clinical outcomes and more effective patient management and safety is a key feature. The manuscript management system is completely online and includes a quick and fair peer-review system. Visit http://www. dovepress.com/testimonials.php to read real quotes from authors.

Submit your manuscript here: https://www.dovepress.com/medical-devices-evidence-and-research-journal 